persists. When forest conservation was introduced into the tropical and sub-tropical portions of the British Empire, fire protection was considered to be one of the first important steps to inaugurate. The success achieved in India in this respect is well known; but, efficient and energetic as the forest service of that country showed itself in the fine system of fire protection introduced into the State forests, it would never have achieved success without vigorous official support. A Science Service Mail Report (Washington, D.C., July 30) states that owing to the drought, there has been a 66 per cent increase in forest fires for 1934 over the average of the past three years. National and State forests have, it is said, become like tinder in a great many areas, and the smallest spark is sufficient to light them. In 1933, there were 140,722 fires, the area burnt being $43,889,820$ acres, the total damage being estimated by the U.S. Forest Service at $60,274,960$ dollars. If the number of fires increases at the same rate as already experienced this year, the totals will exceed those of 1933. Attention is directed to the fact that a sum of $75,000,000$ dollars has recently been earmarked for the 1,300 mile shelter belt of trees extending from the Canadian border to Texas, and the work is expected to continue for ten years. A comparison of the annual expenditure on this new forest belt with the destructive losses from forest fires shows that eight times the money spent each year for the next decade on planting trees would barely equal the value of the loss by fire in 1933 .

\section{Field Museum of Chicago}

THE Field Museum of Natural History, one of the most progressive in the world, has suffered from the adverse financial conditions of the times, which have brought about declines in the value of securities held in endowment funds and reduction in income from endowments, contributions and memberships. Schemes of expenditure have had to be very much curtailed and economies enforced, but the result has been a gratifying reduction of the deficit carried forward from the previous year. Part of the success was due to the influx of visitors to Chicago for the Century of Progress Exposition, for the museum visitors for 1933 numbered $3,269,390$, an annual attendance exceeding that ever attained by any museum in the United States, and probably a high record for the world. The growing fame of the Field Museum has something to do with its success. Consider the two major exhibits opened to the public in 1933: one, the Chauncey Keep Memorial Hall contrining sculptures representing the principal races of mankind, and the Hall of the Stone Age of the Old World, with its restorations of types of prehistoric men and phases of their cultures. Both these new halls are unique-no other institution has exhibits illustrating these subjects on the scale of the Field Museum. In the zoology halls there were added natural groups of African lions, gaurs or seladangs of Asia, Florida manatees, orang-utans, bowerbirds, and many series not treated as natural groups. Expeditions and field work had to be avoided except where they were financed by special funds contributed for the purpose; even so, zoological collecting was carried on in Guadalupe Island, in Guatemala and in West Africa, fossil collecting in Colorado and the eastern States, and archæological excavations on the site of the Lowry ruin in southwestern Colorado.

\section{Agriculture in New Zealand}

IN opening the annual Dominion Conference of the New Zealand Farmer's Union at Wellington, Lord Bledisloe, the Governor-General, reviewed some of the current problems of the agricultural industry. After expressing the view that in no other country has the farmer brighter prospects, he urged the need for 'planning' control if economic success is to be realised. The lack of uniformity that still exists in both the dairy and ca.ttle industries of New Zealand is preventing the extension of markets, and the elimination of second-rate produce must be effected as soon as possible. This cannot be brought about by Government intervention or control, but lies in the hands of the farmers themselves. Comparison with successful agricultural countries, such as Denmark, shows that this type of self-organisation is the most satisfactory. Speaking with reference to the cattle industry, Lord Bledisloe deplored the continuation of the embargo imposed on the importation of British livestock. The measures adopted in Great Britain for the suppression of epidemics such as foot-andmouth disease are so drastic, he said, that the risk of introducing this complaint into New Zealand is nil. On the other hand, the loss to their cattle industry (especially in view of the present hopeful prospect of a remunerative trade in chilled beef and bacon pigs) is a very serious matter. In general, the outlook for the future is a hopeful one, but harmonious co-operation between town and cointry, factory and farm must be achieved if a lasting prosperity is to be assured.

\section{Abattoir Design}

A REPORT on abattoir design has recently been issued (Economic Series, No. 40. H.M. Stationery Office. Price ls. net) by a technical committee appointed by the Ministry of Agriculture and Fisheries last December to consider the output, structure, lay. out and equipment of factory abattoirs. The Committee recommends that the principal characteristics of a factory abattoir should be single control, specialisation of labour, continuous process, the killing being spread fairly evenly over at least four days of the week, and a uniform condition and appearance of the finished product in place of the variations at present existing in the condition not only of the meat but also of the by-products. The Committee prefers a multi-floor factory abattoir to the single floor type found in nearly all the public abattoirs in England, on grounds both of hygiene and economy. It is recommended that in order to raise the general level of the condition of home-killed meat, all the meat and red offals should be adequately cooled before removal. Provision should also be made for 